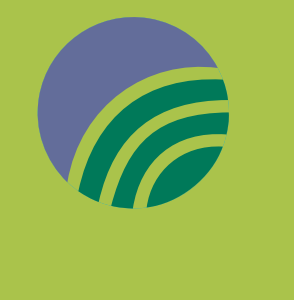

\section{Congressional fellows apply science background to policy development}

$\mathbf{M}$ eet Mirvat Abdelhaq and Andrew Steigerwald — she's a chemist and he's a materials scientist - and they are two of the newest faces on Capitol Hill. They belong to a cohort of scientists, engineers, doctors, and veterinarians who are part of the Congressional Science and Engineering Fellowship Program. This program is a cooperative effort organized by the American Association for the Advancement of Science (AAAS) where participating professional societies (approximately 30 different organizations) sponsor a year-long fellowship to work in the US Congress. The Materials Research Society (MRS) has partnered with the Optical Society of America (OSA) and the Minerals, Metals and Materials Society (TMS) to sponsor Abdelhaq and Steigerwald.

Abdelhaq, the 2012-2013 MRS/OSA Fellow, has chosen to work for Senator Jeff Merkley (Dem-Ore.) on a portfolio of energy and environmental issues. "I feel very fortunate in my placement," says Abdelhaq; "The office has a good track record with fellows and provides them with an opportunity to experience many aspects of the legislative process from meeting with stakeholders, to drafting legislation, to staffing the Senator at committee hearings and markups."

In his placement with Senator Sherrod Brown (Dem-Ohio), 2012-2013 MRS/ TMS Fellow Steigerwald uses his scientific background "several times a day" because he is working on a portfolio of tech-heavy issues that includes advanced manufacturing, energy, and tax policy. His main legislative focus is on the National Network for Manufacturing Innovation (NNMI), an initiative focused on developing and scaling advanced manufacturing technologies and processes through a collaborative nationwide network. "I particularly enjoy the NNMI project because it is a very well conceived, very needed effort that relates well to my background," says Steigerwald.
Abdelhaq agrees that her experience is well utilized on the Hill, saying, "I use the skill set I developed as a scientist everyday_-being self-motivated to learn and understand complex issues, to analyze large sets of information, and to use that information for problem solving." She also adds that she has had the opportunity to use her technical knowledge as a chemist "a number of times on issues related to ocean acidification or toxic chemical reform."

Unlike their PhD training by which both fellows became experts in their respective fields, as scientists on the Hill they are often viewed as general technical experts and are constantly consulted on a broad range of science and engineering topics. Colleagues "know they can use me as a resource on things that they don't understand or have a background in," says Steigerwald. But science is only one factor in the political decision-making process and Abdelhaq points out that her greatest challenge so far "has been coming to terms with the fact that the correct scientific answer may not be the best political answer."

Although science is only one piece of the policy puzzle, both Abdelhaq and Steigerwald encourage scientists and engineers to engage in the political process. According to Abdelhaq, "the most important thing is making your voice heard-your representatives cannot help you if you don't ask them. Be sure your elected officials and their staff realize the significant contributions your work is making toward solving real problems as well as generating tangible results in the community." Steigerwald adds that "especially in times when the budget is being scaled back, it's important for scientists to be able to put a human face on the effects of scaling back science funding and give concrete examples to what happens when we underinvest in basic R\&D [research and development]
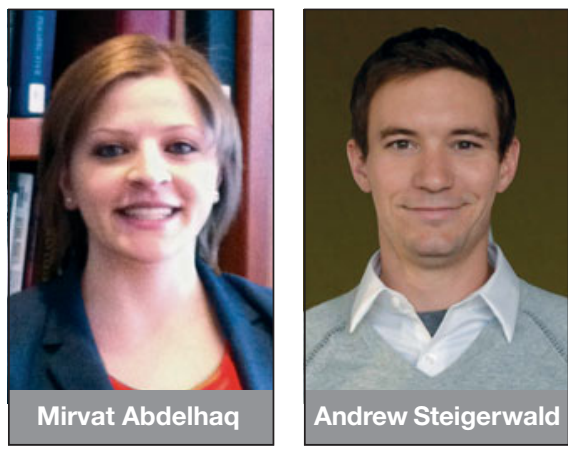

spending. In the absence of real people participating in the process it's impossible to make an effective argument for why we should sustain federal funding for any particular scientific discipline."

Steigerwald also points out the importance of scientists being aware of what is happening in the policy world, "Given a period of fiscal belt-tightening, more emphasis will be placed on public-private partnerships and commercialization efforts. Materials scientists should be paying attention - and provide input if possibleto what ideas and policies develop on this front both for opportunities but also [to understand] how other policy areas will be affected as funds are redirected." And both fellows were quick to point out that the MRS Congressional fellowship has been an excellent opportunity to not only better understand the science-policy relationship but also to be an integral part of the process.

What do these two scientists-turnedpolicy-experts have to say about their fellowship experience so far and what the future might hold post-fellowship? Abdelhaq acknowledges that choosing a good placement makes a significant difference in the fellowship experience, and in Merkley's office she was encouraged to "experience many different aspects of the legislative process." She says that the fellowship has convinced her that she "would like to remain in public service, working on science policy issues." Steigerwald agrees, saying, "the fellowship experience has exceeded my expectations - I've found the whole experience to be very enlightening, challenging, and rewarding." He adds, "I certainly plan on staying in policy."

Jennifer A. Nekuda Malik 2011-2012 MRS/TMS Congressional Fellow 